\title{
Desenvolvimento de Jogos para Incentivar Meninas na Área da Tecnologia de Informação: um estudo de caso no ensino médio de escola pública
}

\author{
Geisiane de Souza Matos¹, Sara M. Silva², Fabiola Pantoja O. Araújo², Yomara \\ Pinheiro Pires', Marcos Cesar R. Seruffo \\ ${ }^{1}$ Campus Castanhal - Universidade Federal do Pará (UFPA) \\ Av. dos Universitários, S/N - 68746-360 - Castanhal - PA - Brasil \\ 2Instituto de Ciências Exatas e Naturais (ICEN) \\ Instituto de Tecnologia (ITEC)- Universidade Federal do Pará (UFPA) \\ Rua Augusto Corrêa, 01 - 66075-110 - Belém - PA - Brasil \\ \{geisi.mattos.s, maru.merces18\}@gmail.com \\ \{fpoliveira, yomara, seruffo\}@ufpa.br
}

\begin{abstract}
This article describes the actions of an experience report that was carried out with high school students of public school of the municipality of Inhangapi (Northeast of Pará), with the objective of approaching the technologies that are part of the areas of Computing. It consists in presenting a teaching methodology of programming logic through the development of educational games in the tool Construct 2. After analyzing the pre and post-project questionnaires, a noticeable influence was identified with a $40 \%$ in the interest to know graduations in Computing areas and an expressive increase of the students in wanting to learn more about game development and programming logic.
\end{abstract}

Resumo. Este artigo descreve as ações de um relato de experiência que foi realizado com alunas do ensino médio de escola pública do município de Inhangapi (Nordeste do Pará), com o objetivo de aproximá-las das tecnologias que fazem parte das áreas da Computação. Consiste em apresentar uma metodologia de ensino da lógica de programação por intermédio do desenvolvimento de jogos educativos na ferramenta Construct 2. Após a análise dos questionários pré e pós-projeto foi identificada uma influência perceptivel com um aumento de $40 \%$ no interesse em conhecer graduações em áreas da Computação e um expressivo aumento das alunas em desejar aprender mais sobre desenvolvimento de jogos e lógica de programação.

\section{Introdução}

Nos últimos anos, a participação feminina no mercado de trabalho teve um aumento significativo. Dados do Instituto de Pesquisa Econômica Aplicada (IPEA), constatou que em 2016 chegou a 59,1\% de registros profissionais. Outra informação relevante, é o fato de que, esse aumento se dá na maior parte por razão da participação de jovens, com idade entre 16 24 anos. Apesar de hoje as brasileiras serem a maioria da população, ainda enfrentam problemas relacionados a desigualdade de gênero, se tornando um fator presente no mercado de trabalho. Nas Instituições de Ensino Superior, a desigualdade é presenciada também nas 
VIII Congresso Brasileiro de Informática na Educação (CBIE 2019)

Anais do XXV Workshop de Informática na Escola (WIE 2019)

áreas de ensino, sendo notada em cursos das áreas de saúde, licenciaturas, exatas e computação, os quais apresentam uma marca expressiva em distinção de gênero na formação das turmas. Dados do Instituto Nacional de Estudos e Pesquisas Educacionais Anísio Teixeira (INEP) divulgou no censo do ensino superior de 2017 o número de matrículas em cursos de Ciência da Computação em um total de 62.660 , com uma taxa de $10 \%$ de concluintes. Nota-se uma baixa porcentagem de alunos que chegam a concluir o curso. Esse contexto se agrava quando falamos da participação feminina. De acordo com a [SBC, 2014] os números de matrículas na área da Computação têm apresentado um crescimento expressivo, porém o número de matrículas de mulheres permanece estagnado. A Pesquisa Nacional por Amostra de Domicílios (PNAD) do Instituto Brasileiro de Geografia e Estatística (IBGE), divulgou em 2016 que, a maioria das mulheres que ingressam no ensino superior em cursos tecnológicos, desistem do curso no primeiro ano da graduação.

Nesse contexto, tem se pensado em iniciativas sobre a minoria de mulheres na área da Computação, buscando identificar os fatores que contribuem para essa realidade, como forma de capacitar mais profissionais, que possam atender à crescente demanda do mercado. É importante acrescentar que a escola é o ambiente ideal para a inserção de novos aprendizados, local esse em que os alunos estão engajados e abertos ao novo. Por tanto, incentivar os alunos das séries do ensino médio pode ser uma iniciativa positiva nesse processo de formação profissional, com uma metodologia de fomento do ingresso de mulheres na Computação. Porém, o processo de aprendizagem da lógica de programação necessita de conhecimentos básicos como fundamentos da matemática, que por si são mais explorados nas escolas [Ribas et al. 2016], sendo esse um dos componentes fundamentais no processo de ensinoaprendizagem. Para [Leal, 2014] o processo do ensino da programação não deve está baseado no aprendizado de linguagens de programação, mais na aprendizagem criativa, que está relacionada as habilidades que se deve desenvolver para a construção de softwares, habilidades estas provenientes dos seus interesses pessoais.

Este artigo consiste na aplicação de uma metodologia de ensino da lógica de programação através do desenvolvimento de jogos, voltado para as meninas do ensino médio de uma escola pública do município de Inhangapi interior do estado do Pará, que teve como objetivo divulgar áreas da Tecnologia e Computação para meninas, com o propósito de despertar o interesse desse público por meio da experimentação e estimulo de descobertas, em carreiras da Computação. Esta proposta está em sintonia com projetos de fomento realizados pela $\mathrm{SBC}$, como o programa Meninas Digitais, que "tem como objetivo divulgar a área da Computação e suas tecnologias para despertar o interesse de meninas estudantes do ensino médio e dos anos finais do ensino fundamental" (Meninas Digitais, 2019).

Este artigo está estruturado da seguinte forma: na Seção 2 são apresentados os trabalhos relacionados a está proposta e os pontos que se assemelham e diferenças, na Seção 3 é descrito a metodologia de desenvolvimento do projeto dividida em dois tópicos, atividades do projeto e jogo desenvolvido. Na Seção de número 4 são apresentados os resultados dos questionários pré e pós projeto em uma análise quanti-qualitativa. Por fim, na Seção 5 são apresentadas as considerações finais deste trabalho.

\section{Trabalhos que relatam o ensino da lógica de programação}

Em [Ramos et al 2015], é apresentado o desenvolvimento de um aplicativo com a ferramenta MIT App Inventor, com o tema copa do mundo. O objetivo é despertar nas meninas o interesse 
VIII Congresso Brasileiro de Informática na Educação (CBIE 2019)

Anais do XXV Workshop de Informática na Escola (WIE 2019)

pela área da computação. O projeto é avaliado nos resultados como satisfatório pois alcançou o objetivo proposto, por meio do comprometimento das alunas participantes, sendo entregue ao final do projeto o aplicativo desenvolvido. Este estudo foi avaliado somente com coleta via questionário ao final das atividades. [Coutinho et al. 2018] destaca a importância da lógica de programação e o esforço empreendido por parte dos docentes, que buscam por uma maneira de associar a teoria com a prática de forma que os alunos consigam desenvolver as atividades, empregando conceitos aprendidos. Nesse estudo é relatado a experiência do ensino da lógica de programação a alunos da graduação, utilizando uma ferramenta de desenvolvimento de jogos, com o objetivo de auxiliar nas disciplinas da grade curricular de ensino.

No trabalho de [Bonfim et al. 2018] é relatada a experiência do incentivo às meninas as áreas da Computação através da interação do design participativo. Neste estudo é enfatizado o desenvolvimento de aplicativos com tema do empoderamento feminino e inclusão digital. Sendo o projeto avaliado por meio de um questionário aplicado no pós-projeto (final das atividades). Nesta proposta os autores realizam a descrição das atividades e as perspectivas do ponto de vista das alunas referentes a tecnologia e Computação.

Portanto, este trabalho se assemelha em alguns pontos e se diferencia em outros, pois se propõe a elaborar uma proposta de ensino da lógica de programação em uma abordagem construtivista a meninas do ensino médio de escola pública, utilizando uma aplicação de desenvolvimento de jogos no processo de ensino, buscando estimular práticas até então desconhecidas. A proposta visa orientar as estudantes sobre o que representa a Computação e a participação feminina nesta área; bem como desenvolver habilidades através do pensamento algoritmo/computacional. Uma outra diferença é a avaliação da metodologia utilizada, identificando os pontos de falha, ajustes da metodologia e aplicá-la novamente ao grupo que apresentou dificuldades.

\section{Metodologia de desenvolvimento do projeto}

Este trabalho foi aplicado às alunas das turmas de $1^{\mathrm{a}}, 2^{\mathrm{a}}$ e $3^{\mathrm{a}}$ ano do ensino médio, sendo divididas em dois grupos, turma $\mathrm{A}$ com as atividades desenvolvidas no período matutino, com um total de 8 participantes e, a turma B no horário vespertino e 14 participantes, no qual a faixa etária foi de 16 a 24 anos. Foi realizado o desenvolvimento de aulas teóricas e práticas de lógica de programação, focando no desenvolvimento de jogos lúdicos voltado para as habilidades que a lógica de programação oferece, como o trabalho em equipe, resolução de problemas através da prática, criatividade, raciocínio lógico e pensamento computacional

Para o desenvolvimento deste projeto foram realizadas quatro fases macros, sendo avaliadas por coleta de dados quanti-qualitativos. A primeira é referente a realização das aulas, que se deram após a aplicação do questionário pré-projeto, divididas entre aulas teóricas e aulas práticas. A segunda é a fase pós projeto (após a aplicação do questionário), que se caracteriza em verificar o desempenho das alunas em relação ao desenvolvimento das atividades propostas. A terceira é a aplicação da aula de reforço para as alunas que apresentaram dificuldades na elaboração das atividades, visando suprir áreas de baixo desempenho. Por fim, a última fase é marcada pela reaplicação do questionário pós projeto, somente para o grupo que apresentou dificuldades, com o objetivo de avaliar a melhora na metodologia após a aula de reforço. $\mathrm{Na}$ aula de reforço foi feito um acompanhamento 
VIII Congresso Brasileiro de Informática na Educação (CBIE 2019)

Anais do XXV Workshop de Informática na Escola (WIE 2019)

individual com o grupo que apresentou dificuldades. A aula aconteceu em grupo para as 4 participantes, que apresentaram dificuldades durante o processo de desenvolvimento do jogo.

\subsection{Atividades do projeto}

A primeira atividade consistiu na exposição de uma palestra com o tema "Personalidades Femininas da Computação". Nesse primeiro contato foi apresentada a importância da presença feminina nas tecnologias digitais da informação e comunicação e as contribuições realizadas para a computação ao longo dos anos, como em agências espaciais, criação do primeiro algoritmo e as programadoras do primeiro computador. Em seguida, ainda na primeira aula, foi aplicado o questionário pré-projeto, com perguntas de cunho socioeconômica e sobre a interação computacional das participantes, a fim de traçar um perfil das alunas. Como segunda atividade, foram realizadas duas aulas teóricas nas quais foram abordados os conceitos de algoritmos e lógica de programação, com exemplos do cotidiano de todas, buscando produzir uma analogia real do significado de algoritmos. Durante as aulas teóricas de algoritmos, as alunas utilizaram a ferramenta computacional Visualg para executar seus algoritmos.

Nas aulas seguintes, foi dada ênfase à programação do jogo. Como proposta, as alunas tiveram que desenvolver um jogo que aborda o assunto "mulheres na computação". A partir desse momento, foram trabalhados níveis de programação, sendo realizada primeiro a programação da tela principal e em seguida a programação do tabuleiro de jogo, dividindo os elementos que fariam a composição do jogo. Como desafio, as alunas deveriam identificar os componentes vistos em sala, que seriam essenciais para o funcionamento do jogo, e organizá-los em ordem de importância. Nessa atividade o objetivo era despertar o pensamento computacional das alunas de forma coletiva durante a aula. No segundo momento, as alunas de forma individual passaram a desenvolver todo o processo de criação do jogo desde a concepção da ideia, planejamento do jogo, implementação e apresentação do resultado final.

\subsection{Jogo desenvolvido}

Para a construção do jogo foi utilizada a ferramenta Construct 2, pois é uma ferramenta gratuita, com funcionamento offline. Devido às alunas não possuírem acesso à Internet no laboratório da escola recai a importância da utilização de uma ferramenta instalável.

Como proposta foi sugerido o jogo da memória que, além de trabalhar a lógica, permitiu o uso de personagens femininas do universo computacional e as suas respectivas contribuições para o avanço da Computação (Figura 1). O objetivo principal do jogo é identificar os pares corretos das cartas em um menor tempo e quantidade de tentativas. São oito pares de cartas, o jogador deve virar uma carta e tentar identificar o local onde seu par correspondente está no tabuleiro. Cada par de carta possui uma personalidade feminina da Computação e uma descrição da sua relação com a referida área. 
VIII Congresso Brasileiro de Informática na Educação (CBIE 2019)

Anais do XXV Workshop de Informática na Escola (WIE 2019)

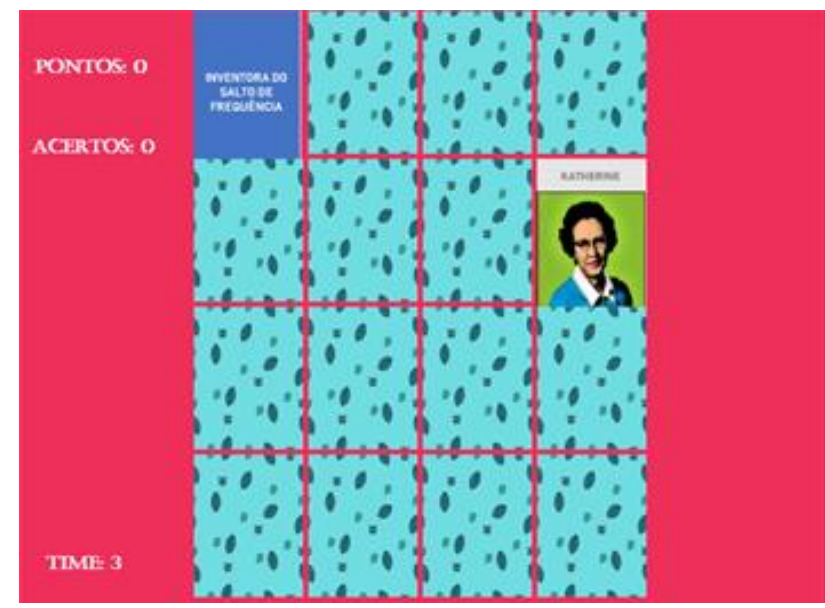

Figura 1. Design do Jogo construído por alunas

Ao final do processo de construção do jogo, as alunas passaram pelo desafio final: como proposta e com as lições aprendidas até então, deveriam alterar a estrutura visual do jogo e algo referente a lógica (organização das cartas no tabuleiro, forma de comparação das cartas, marcação dos pontos no placar, etc.). Esse momento permitiu que fosse avaliado o grau de aprendizagem das alunas e a identificação dos pontos de dificuldades. Após o desafio foi identificado que 4 alunas não conseguiram alterar a lógica do jogo, sendo necessário então a aplicação da aula de reforço. Na aula de reforço foram trabalhados os pontos de dificuldades relatados pelas alunas sendo eles, a sintaxe utilizada pelo programa, declaração de variáveis e atribuição de valores e diferença entre eventos e ações (base principal do Construct 2).

Ao final, os jogos desenvolvidos foram apresentados para a professora do curso e a diretora da escola.

\section{Resultados}

Os resultados do projeto podem ser descritos sob a perspectiva de três momentos: a avaliação do projeto feita pela lista de frequência aplicada às aulas; avaliação das alunas participantes em questões econômicas e do uso de tecnologias; avaliação das atividades realizadas com mapeamento dos pontos positivos e negativos do projeto.

\subsection{Frequência das participantes do projeto}

A Figura 2 mostra a presença das alunas das turmas A e B no decorrer do projeto. A evasão das alunas durante o curso foi considerada baixa, com desistência de apenas duas participantes, com uma frequência superior a $80 \%$ de participação em todas as aulas. De um total de 22 alunas que iniciaram o curso, 20 conseguiram finalizar o projeto.

Outro dado importante retirado da frequência é o fato de as alunas em algumas aulas não comparecerem. Como o curso teve uma duração relativamente curta, uma falta poderia acarretar na queda do resultado final, sendo a metodologia da lógica de programação uma estrutura encadeada de informações. Na análise das participantes desistentes e faltosas, foram reveladas as possíveis causas que levaram a esse resultado, sendo elas: horário das aulas em contra turno com as disciplinas da grade curricular; dificuldades no transporte escolar para a 
VIII Congresso Brasileiro de Informática na Educação (CBIE 2019)

Anais do XXV Workshop de Informática na Escola (WIE 2019)

locomoção das alunas; falta de familiaridade com o computador, o que pode ter causado desmotivação nas participantes do projeto.

$\mathrm{Na}$ avaliação da frequência, com a média de presença em 18 alunas por aula, percebe-se a necessidade de uma busca por novas oportunidades, o que pode ter motivado as alunas a permanecerem durante todas as atividades do projeto. Sendo o curso de ensino da lógica de programação, uma abertura de novos horizontes que norteiam as perspectivas positivas de um futuro promissor, oferecido pelo conhecimento de novas áreas de ensino.

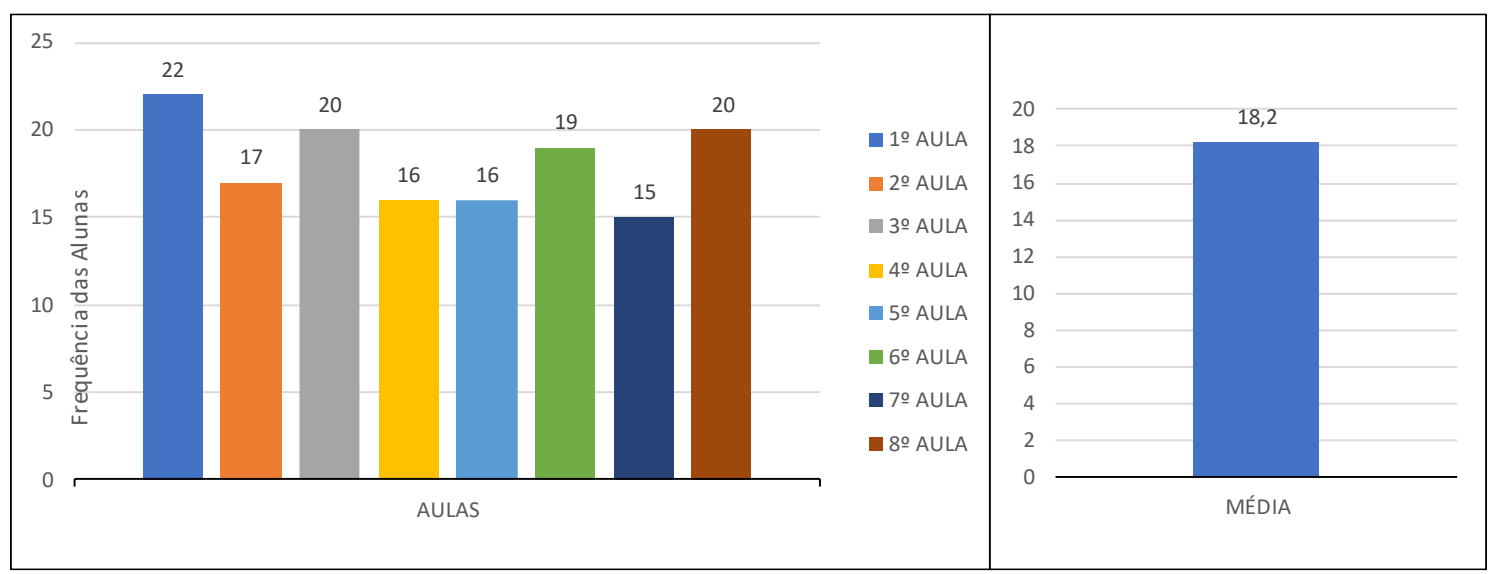

Figura 2. Frequência das alunas durante o projeto.

\subsection{Avaliação das alunas participantes em questões econômicas e do uso de tecnologias}

A avaliação das alunas por meio de questionário teve dois momentos, o primeiro foi aplicado antes do início das aulas, durante a fase pré-projeto. Este questionário teve como objetivo a avaliação socioeconômica das participantes, pois existia uma necessidade de entendimento da realidade do público-alvo do projeto e a avaliação da interação computacional, com perguntas que abordavam assuntos que seriam vistos durante as aulas e questionamentos sobre o que pensam a respeito da Computação. Na avaliação socioeconômica, o questionário continha 7 questões de múltipla escolha e foi respondido por 22 participantes das turmas A e B de forma anônima. Dos resultados obteve-se as seguintes informações: $22 \%$ das alunas são do $1^{\circ}$ ano do ensino médio, $54 \%$ do $2^{\circ}$ ano do ensino médio e $22 \%$ do $3^{\circ}$ ano do ensino médio. Quando perguntado em qual rede de ensino as alunas cursaram o ensino fundamental, foi respondido que $77 \%$ das alunas cursaram todo na rede pública e $23 \%$ maior parte na rede pública. Quanto ao questionamento se possuem interesse em cursar um nível superior, $100 \%$ das alunas responderam que sim, porém ao informar a área de interesse nenhuma das participantes mencionaram cursos da Computação, sendo as principais áreas de possível atuação: saúde (cursos de Enfermagem e Farmácia), Pedagogia e Direito.

$\mathrm{Na}$ avaliação da interação computacional haviam 9 questões, sendo a primeira sobre possuírem algum equipamento tecnológico em casa como "smartphone", tablet, smart TV, computador e a opção de não possuir, ressaltando que poderiam ser selecionadas mais de uma alternativa. Foi informado que $36 \%$ das alunas possuem celular, $13 \%$ computador, 9\% tablet, $31 \%$ smart TV e $31 \%$ não possui contato com nem um dos equipamentos informados. De forma expressiva, $31 \%$ das afirmativas informadas foi a de não possuir nem uma das alternativas de aparelhos em casa. Esse dado é respondido pela circunstância das alunas pois as mesmas residirem na zona rural do município, onde não possui acesso à Internet. Portanto, 
VIII Congresso Brasileiro de Informática na Educação (CBIE 2019)

Anais do XXV Workshop de Informática na Escola (WIE 2019)

apesar da tecnologia ser hoje algo comum para a sociedade, ainda existem grupos isolados que não se beneficiam dessa realidade, principalmente nas áreas afastadas dos grandes centros.

No que tange ao horário de permanência na Internet, as alunas que possuem acesso responderam que $45 \%$ ficam em média menos de 2 horas, $31 \%$ entre 2 e 5 horas, $9 \%$ de 5 a 10 horas e $13 \%$ mais de 10 horas. Outro dado extraído do questionário pré-projeto é referente ao conhecimento das alunas sobre lógica de programação, no qual $77 \%$ das alunas informaram não saber o que é lógica de programação, $19 \%$ já ouviu falar sobre e $4 \%$ não soube informar.

Quando perguntadas se conhecem alguma mulher que trabalha ou trabalhou em área da Computação a resposta foi expressivamente negativa pois $90 \%$ afirmam que não tem informações sobre mulheres na computação e $10 \%$ afirmam conhecer. Em relação a existência de projetos que envolva tecnologia e que sejam voltados para meninas, $100 \%$ das alunas disseram que desconhecem projetos desse tipo. Por fim foi perguntado se as alunas teriam vontade de cursar uma graduação na área de tecnologia, como por exemplo, Ciência da Computação, Engenharia da Computação, Sistemas de Informação ou Análise e Desenvolvimento de Sistemas.

No gráfico da Figura 2, 46\% responderam que provavelmente sim. Essa incerteza pode estar relacionada à falta de conhecimento do que essas áreas estudam e atuam, devido não serem amplamente divulgadas em comparação, por exemplo, com cursos de Pedagogia, Enfermagem ou Direito. A falta de informação é o principal ponto que deve ser tratado nesse contexto de melhorar a divulgação desses cursos para meninas.

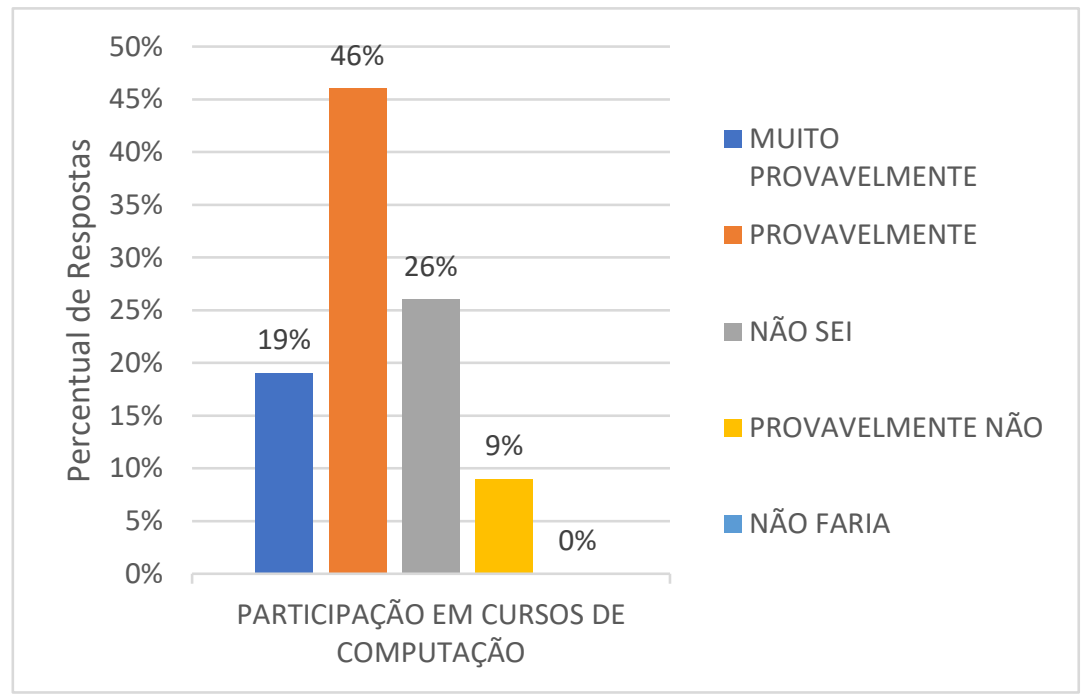

Figura 2. Gráfico do interesse em ingressar em cursos da área da Computação

\subsection{Avaliação das atividades realizadas}

Quanto a avaliação das atividades realizadas em sala referente ao desenvolvimento do jogo, foi aplicado um segundo questionário com o objetivo de avaliar o pós-projeto. Nesse questionário buscou-se identificar os fatores de dificuldade durante as atividades, a motivação das alunas em participar e o envolvimento delas em relação ao domínio da 
VIII Congresso Brasileiro de Informática na Educação (CBIE 2019)

Anais do XXV Workshop de Informática na Escola (WIE 2019)

ferramenta Construct 2. Como primeira informação, $75 \%$ se sentiram muito motivadas e $25 \%$ pouco motivadas. A questão da motivação pode ter relação com a didática utilizada em sala, pois a cada dificuldade em desenvolver as atividades as alunas podem ter se sentido frustradas, devido à falta de controle dos elementos computacionais, como por exemplo manuseio do computado,r elevando assim os fatores de desmotivação. Quanto ao grau de aprendizagem sobre os assuntos abordados, $45 \%$ responderam que o aprendizado foi ótimo, $45 \%$ bom e $10 \%$ se sentiu neutra, não sabendo informar.

No questionário pós-projeto haviam questionamentos sobre a ferramenta utilizada e o tempo de adaptação fornecido durante o curso para seu uso. Como resposta $60 \%$ das alunas relatou que o tempo foi bom, $25 \%$ ótimo, $10 \%$ informou que o tempo de adaptação foi ruim e $5 \%$ não soube responder.

Outra informação relevante é o que contribuiu durante o curso para que as alunas tivessem mais dificuldades em desenvolver as atividades. Nesta pergunta, as alunas poderiam selecionar mais de uma alternativa e o resultado é apresentado no gráfico da Figura 3. A maior frequência de respostas foi utilizando o computador, devido à falta de conhecimento das alunas sobre assuntos da informática básica. Isso motivou ao desenvolvimento de dificuldades que se combinava com a utilização do programa, pois para o bom manuseio da ferramenta era essencial o aprendizado básico de conceitos da informática, como utilização do teclado por meio de teclas de atalho e o próprio mouse.

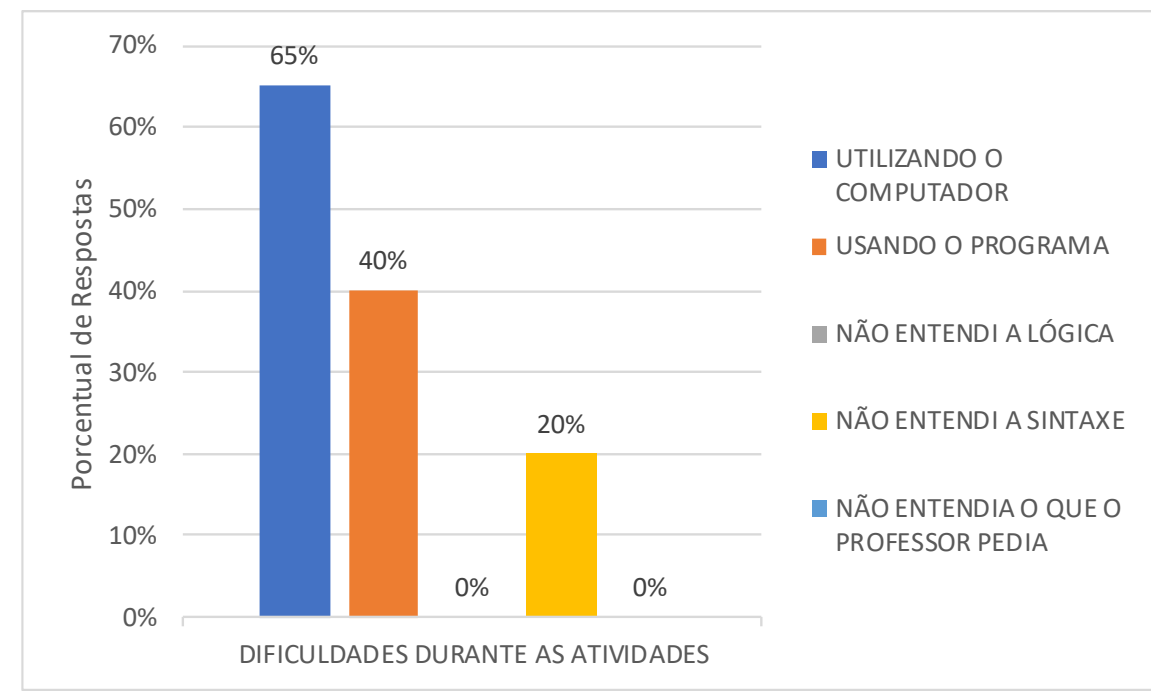

Figura 3. Gráfico das dificuldades enfrentadas durante o curso.

Referente à lógica de programação utilizada no jogo, foi verificado que $5 \%$ acharam muito difícil, $15 \%$ difícil, 30\% acharam um pouco difícil e 50\% não informaram. Foi proposto como desafio a modificação do que havia sido feito como mencionado anteriormente, sendo relatado que $100 \%$ das alunas conseguiram modificar algo referente a lógica de programação e a estrutura visual do jogo final, no entanto algumas dessas alunas só conseguiram o feito após passarem pela aula de reforço.

Ao serem questionadas novamente sobre o interesse em áreas da Computação após a finalização do projeto, tem-se uma diferença dos resultados informados anteriormente. Das 20 alunas que finalizaram as atividades do projeto $65 \%$ demonstraram ter muito interesse, 
VIII Congresso Brasileiro de Informática na Educação (CBIE 2019)

Anais do XXV Workshop de Informática na Escola (WIE 2019)

$25 \%$ provavelmente sim e $10 \%$ não souberam responder. A relação dos resultados pré e pósprojeto é apresentado na Tabela 1 . Por fim, quando questionadas se gostariam de aprender mais sobre jogos e programação, $100 \%$ das alunas responderam positivamente.

Tabela 1. Comparação de resultados pré e pós-projeto referente a participação em cursos da computação.

\begin{tabular}{|c|c|c|}
\hline RESPOSTA & PRÉ-PROJETO & PÓS-PROJETO \\
\hline Não Faria & $0 \%$ & $0 \%$ \\
\hline Provavelmente não & $9 \%$ & $0 \%$ \\
\hline Não sei & $26 \%$ & $10 \%$ \\
\hline Provavelmente sim & $46 \%$ & $25 \%$ \\
\hline Faria com certeza & $19 \%$ & $65 \%$ \\
\hline
\end{tabular}

Diante desses resultados percebe-se que há um grande interesse das meninas pela área da Computação e tecnologias, quando na avaliação pós-projeto tem-se um aumento superior a $40 \%$ de aceitação em conhecer os cursos da Computação. Porém, faltam iniciativas que possam oportunizar o contato delas com esse universo até então desconhecido. Esse resultado é mais latente no contexto Amazônico, principalmente em municípios ribeirinhos como o caso de Inhangapi, que tem sua subsistência baseada em atividades pesqueiras e de agricultura familiar, levando as adolescentes a ingressarem nessas atividades com o objetivo de ajuda no sustento familiar.

A abordagem do ensino da lógica de programação por meio do desenvolvimento de jogos, método utilizado neste relato de experiência com meninas do ensino médio de uma escola pública, foi relevante para a concretização deste trabalho, principalmente porque para este modelo de estudo foi preciso realizar a descrição detalhada dos relatos de ensino e, consequentemente a extração e análise qualitativo e quantitativa dos mesmos. Alguns fatores de relevância do ensino da lógica de programação devem ser destacados como o desenvolvimento de habilidades por meio da abordagem de pensamento computacional e aprendizagem criativa, habilidades hoje imprescindíveis para a educação 4.0 e a possibilidade de aproximação das alunas as tecnologias que habitualmente manuseamos, apresentando assim o outro lado do conhecimento passado de consumidores de tecnologia para entender um pouco sobre a produção [Resnick, 2012].

\section{Conclusão}

Este projeto proporcionou para as alunas, a oportunidade de conhecer um pouco sobre o mundo da Computação. Foi capaz de despertar o interesse em assuntos da lógica de programação e desenvolvimento de jogos, além de possibilitar às alunas, conhecimento de parte da história de contribuição das mulheres na Computação, para que percebessem a importância da presença feminina nesse setor, principalmente pelo fato das alunas fazerem parte da região nordeste do estado do Pará, contexto Amazônico e comunidade ribeirinha.

Mediante os acontecimentos, pode-se compreender a importância do projeto para as alunas, no momento em que se obteve um aumento de $19 \%$ para $65 \%$ em interesse na participação em cursos da área da computação. Dessa forma o objetivo desse projeto foi alcançado com resultados satisfatórios, que se propôs em despertar o interesse de meninas do ensino médio em carreiras das áreas da Computação e suas tecnologias, podendo elas serem incentivadas através do conhecimento de tecnologias e desenvolvimento de jogos. Ficando comprovado a satisfação das alunas em participar de todo o processo de desenvolvimento de 
VIII Congresso Brasileiro de Informática na Educação (CBIE 2019)

Anais do XXV Workshop de Informática na Escola (WIE 2019)

um jogo, desde a fase de concepção da ideia até a apresentação final. Além de relatar que $100 \%$ das alunas participantes desejam aprender mais sobre lógica de programação e desenvolvimento de jogos.

Como evolução desta proposta, é sugerido que o projeto seja ampliado, passando a ter um cronograma, com diferentes atividades que possam desenvolver nas alunas habilidades da informática básica. Também é importante montar eventos ao final do projeto para a apresentação dos trabalhos desenvolvidos, buscando motivar as alunas durante as atividades, com a proposta de uma exposição dos jogos construídos. Outra importante contribuição, seria em projetos futuros além da ampliação em outras escolas, a possibilidade de montar palestras com mulheres (representação regional) que desempenham um papel na Computação, sendo possível despertar nas meninas por meio de exemplos a importância do empoderamento feminino na sociedade computacional.

\section{Referências}

Instituto de Pesquisa Econômica Aplicada - IPEA. (2017). A Inserção da Mulher no Mercado de Trabalho. Sistema de Pesquisa de emprego e desemprego. 2017.

Instituto Brasileiro de Geografia E Estatística - IBGE. (2019). Disponível em: <http://. ibge.gov.br>. Acesso em maio, 2019.

Instituto Nacional de Estudos e Pesquisas Anísio Teixeira - INEP. (2019). Disponível em: $<$ http://portal.inep.gov.br/web/guest/inicio>. Acesso em maio, 2019.

CSBC-Wit. (2014). WIT - Women in Information Technology. XXXIV Congresso da Sociedade Brasileira de Computação - CSBC 2014. Disponível em: $<$ http://csbc2014.cic.unb.br/index.php/wit>. Acesso em abril, 2019.

Ribas, E., Bianco, G. D., e Lahm, R. A. (2016). Um curso de programação a distância com metodologias ativas e análise de aprendizagem por métricas de software. ' RENOTE Revista Novas Tecnologias na Educação.

Leal, Alexis Vinícius de Aquino. Ensino de programação de computadores no ensino médio integrado [manuscrito]: uma abordagem utilizando padrões e jogos com materiais concretos / Alexis Vinícius de Aquino Leal - 2014.

Programa Meninas Digitais. (2019). Disponível em: $<$ http://meninas.sbc.org.br/>. Acesso em julho, 2019.

Ramos, Nadja. Et al. (2015). Ensino de Programação para Alunas de Ensino Médio: Relato de uma Experiência. Disponível em: $<$ http://www.lbd.dcc.ufmg.br/colecoes/wei/2015/040.pdf > . Acesso em julho, 2019.

Coutinho, E. F., Bonates, M. F., Moreira, L. O. (2018). Relato sobre o Uso de uma Ferramenta de Desenvolvimento de Jogos para o Ensino Introdutório de Lógica de Programação. In VII CBIE - Workshops do VII Congresso Brasileiro de Informática na Educação.

Bonfim, C. J. L., Martins, A. B. N., Mombach, J. G., Sousa, J. K. L. (2018). Desenvolvimento de Aplicativos Móveis por Meninas: Uma Abordagem Participativa. In VII CBIEWorkshops do VII Congresso Brasileiro de Informática na Educação.

Resnick, M. Mother's Day, Warrior Cats, and Digital Fluency: loriesfrom the Scratch online Community. In: Conference Constructionism: Theory, Pratice and Impact, 2012. 